\title{
Manifestations of the earthquake preparations in the ionosphere total electron content variations
}

\author{
Alexander A. Namgaladze*, Oleg V. Zolotov, Mikhail I. Karpov, Yulia V. Romanovskaya \\ Department of Physics, Murmansk State Technical University, Murmansk, Russia; ${ }^{*}$ Corresponding Author: namgaladze@yandex.ru
}

Received 1 July 2012; revised 10 August 2012; accepted 17 August 2012

\begin{abstract}
Recent ionospheric observations report anomalous total electron content (TEC) deviations prior strong earthquakes. We discuss common features of the pre-earthquake TEC disturbances on the basis of statistics covering $\mathbf{5 0}$ strong seismic events during 2005-2006. The F2-layer ionospheric plasma drift under action of the electric fields of seismic origin is proposed as the main reason of producing TEC anomalies. The origin of such electric fields is discussed in terms of the lithosphere-atmosphere-ionosphere coupling system. This theory is supported by numerical simulations using global Upper Atmosphere Model (UAM). UAM calculations show that the vertical electric current with the density of about $20-40 \mathrm{nA} / \mathrm{m}^{2}$ flowing between the Earth and ionosphere over an area of about 200 by $2000 \mathrm{~km}$ is required to produce the TEC disturbances with the amplitude of about $30 \%-50 \%$ relatively to the non-disturbed conditions. Ionosphere responses on the variations of the latitudinal position, direction and configuration of the vertical electric currents have been investigated. We show that not only the vertical component of the ionospheric plasma drift but also horizontal components play an important role in producing preearthquake TEC disturbances.
\end{abstract}

Keywords: Lithosphere-Atmosphere-lonosphere Coupling System; Ionospheric Earthquake Precursors; Total Electron Content of the Ionosphere; Electromagnetic Plasma Drift; Global Electric Circuit; Vertical Electric Current

\section{INTRODUCTION}

The ionosphere of the Earth is no doubt an important part of the global electric circuit and is a subject to dramatic perturbations related mainly with geomagnetic and solar activity. It also reacts on going from "below" im- pacts from different processes like thunderstorms, dust storms, radioactive pollutions, volcanic eruptions, earthquakes, etc. Recently the total electron content (TEC) of the ionosphere became one of the most often used parameter to describe features of the ionosphere behavior before, during and after the considered seismic events. TEC is the total number of electrons along the vertical path between the satellite and the ground in $1 \mathrm{~m}^{2}$ cross section column; TEC is measured in TEC units $(1 \mathrm{TECu}=$ $10^{16} \mathrm{el} / \mathrm{m}^{2}$ ). It is derived from the regular ionosphere observations using GPS and GLONASS satellites (as sources of stable signals) and ground-based network of receivers of these signals.

Basing on numerous ground-based and satellite observations many papers reported significant ionosphere disturbances (including the TEC increases or depressions) existing during quiet periods of the geomagnetic and solar activity. As these disturbances happen just before and spatially near the earthquakes' locations many investigators consider these ionosphere anomalies as precursors. Nevertheless the current knowledge state and field of the investigation are far from making reliable EQ' forecasts.

This paper provides a summary of our investigations' results in the field of the pre-earthquake TEC variations. We present the pre-earthquake GPS-observed TEC disturbances analysis' results for 50 cases of $\mathrm{M} \geq 6$ seismic events happened during 2005-2006, and propose a physical interpretation for considered seismo-ionosphere anomalies supported by the Upper Atmosphere Model (UAM) numerical calculations.

\section{TOTAL ELECTRON CONTENT PRE-EARTHQUAKE DISTURBANCES' FEATURES}

Numerous case studies reported the following features of the TEC disturbances observed before strong earthquakes [1-8] (see Figure 1).

- Anomalous strong ( $\geq 30 \%$ - $90 \%$ relatively to the quiet values) positive or negative modifications (increases or reductions) before $\mathrm{M} \geq 5$ earthquakes linked to the 
TEC disturbances (\%),

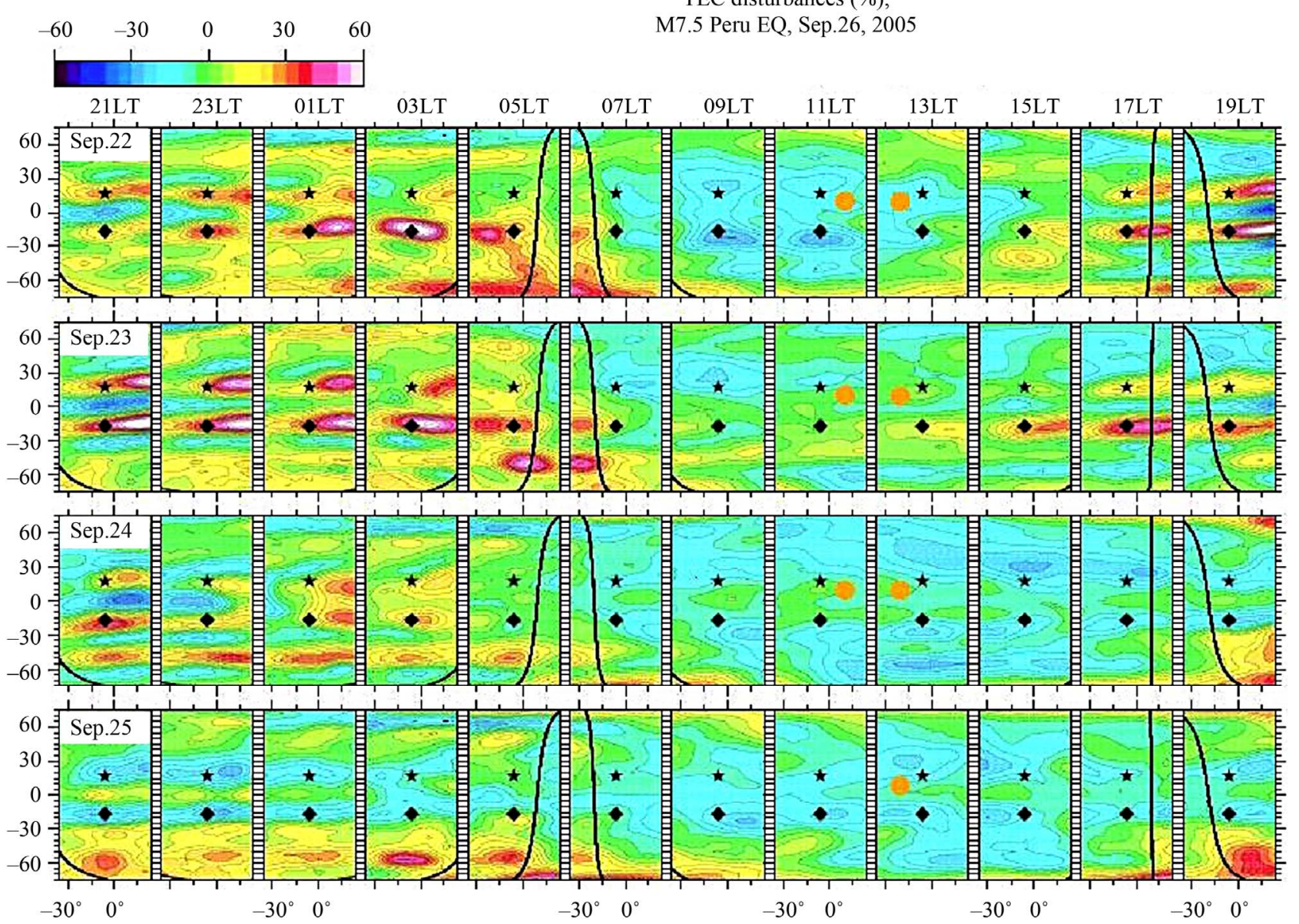

Figure 1. TEC disturbances (\%) relative to non-disturbed conditions prior to the Peru earthquake [6], September 26, 2005. Star and diamond denote the epicenter position and the magnetically conjugated point respectively. Black line and orange circle correspond to the terminator and sub-solar point. Coordinates are the geomagnetic latitude and longitude. Local time labels corresponds to the earthquake' epicenter position.

near-epicenter area. According to $[7,8]$ the positive anomalies are more often observed.

- The size of the anomalies depends on the earthquake magnitude and extends larger than $1500 \mathrm{~km}$ in latitude and $3500-4000 \mathrm{~km}$ in longitude. The structure and dimensions of the disturbed areas are kept rather stable during $4-8$ hours. These anomalies do not propagate along the magnetic meridians in contrast of the ionospheric disturbances caused by solar and geomagnetic activities.

- Local long-living negative and positive disturbances are reported to appear from several hours to couple of weeks before the earthquake's release moment. The sign of the anomaly may change to the opposite one. Sometimes anomalies depress up to full decay before the earthquake release moment or a few hours earlier.

- The vertical projection of the epicenter does not mandatory coincides with the maximum phenomenon's manifestation location.
- Similar effects are often observed at the magnetically conjugated region.

- In case of the strong low-latitudinal earthquakes increase or decrease of the equatorial anomaly with the trough deepening and filling takes place [9-11].

This set of the features was extended with terminator and sub-solar point effects in [11-14].

- Relative TEC disturbances reduce sometimes to almost full disappearance when the ionosphere conductivity increases, i.e., with the sunrise terminator and sub-solar point income.

- The disturbed areas shift from the terminator to the night-sector. TEC disturbances' renewal takes place after sunlit ionosphere (sunset terminator) leave.

Table 1 presents the results of application of this feature-list for 2005-2006, $-50^{\circ}<\varphi<50^{\circ}, \mathrm{M} \geq 6, \mathrm{D}<60$ $\mathrm{km}$ earthquakes, where $\varphi$ is the considered seismic event epicenter's magnetic latitude [6]. The criteria were even hardened - we strongly required the geomagnetic conjugation of the pre-EQ TEC anomalies. According to the 
Table 1. Number of seismic events with ionospheric precursors during 2005-2006.

\begin{tabular}{|c|c|c|c|c|c|c|}
\hline \multirow{3}{*}{$\begin{array}{c}\text { Total number } \\
\text { of considered events }\end{array}$} & \multicolumn{3}{|c|}{2005} & \multicolumn{3}{|c|}{2006} \\
\hline & $\begin{array}{l}\text { Equatorial } \\
\qquad\left( \pm 10^{\circ}\right)\end{array}$ & $\begin{array}{c}\text { Low } \\
\left(10^{\circ}-30^{\circ}\right)\end{array}$ & $\begin{array}{c}\text { Middle } \\
\left(30^{\circ}-50^{\circ}\right)\end{array}$ & $\begin{array}{l}\text { Equatorial } \\
\qquad\left( \pm 10^{\circ}\right)\end{array}$ & $\begin{array}{c}\text { Low } \\
\left(10^{\circ}-30^{\circ}\right)\end{array}$ & $\begin{array}{c}\text { Middle } \\
\left(30^{\circ}-50^{\circ}\right)\end{array}$ \\
\hline & 14 & 12 & 3 & 6 & 13 & 2 \\
\hline Events with precursors & 11 & 10 & 1 & 3 & 8 & 0 \\
\hline Only positive precursors & 6 & 7 & 1 & 2 & 4 & - \\
\hline Only negative precursors & 2 & 1 & - & 1 & 1 & - \\
\hline Both positive and negative precursors & 3 & 2 & - & - & 3 & - \\
\hline Anomalous precursors ${ }^{\mathrm{a}}$ & 3 & 4 & - & - & 3 & - \\
\hline
\end{tabular}

${ }^{a}$ Here in this table term "anomalous precursors" denotes that the anomaly happened at day-time hours when the solar ionization had maximal values. To appear at this time extremely high values of the electric fields are required due to the increased ionospheric conductivity.

analysis, the TEC disturbances satisfying that strengthened criteria were revealed in two thirds of all investigated events (see Table 1). This investigation does not count false-cases of the kind when the precursor was revealed but no earthquake happened as the events for analysis were selected from USGS (US Geological Survey) earthquakes' catalog.

It also should be mentioned that studies $[6,14,15]$ confirmed the set of morphological features mentioned earlier in this section. We expect it to be developed further in order to improve the existing earthquakes' forecast technique.

\section{PHYSICAL MECHANISM}

There is no common opinion in scientific society on the physical mechanism that could explain the penetration of the seismic preparation processes' impact into the ionosphere. It is still a subject of discussion and detailed review of the proposed physical mechanisms may be found in [5,16-19]. In short, two channels of penetration are proposed: the wave channel (including Acoustic Gravity Waves) and electromagnetic channel. As there is no presence of the wave signatures of the discussed TEC disturbances we reject the neutral atmosphere wave channel. We strongly believe that the ionospheric response on the pre-seismic processes is explained in terms of the electromagnetic channel as will be discussed further.

It should be mentioned that NmF2 and TEC disturbances related with magnetic activity are created by the neutral atmosphere (neutral gas composition- $\mathrm{O} / \mathrm{N}_{2}$ ratio, internal gravity waves and winds) and electric field variations. But it is impossible to localize the neutral atmosphere disturbances at a limited area as they will propagate away from the source. So we reject mechanism of producing ionospheric disturbances during earthquake preparation by the neutral atmosphere variations because the TEC disturbances' position is rather stable as it has been noticed earlier.
We consider previously set hypothesis of the vertical drift of the F2-layer ionospheric plasma under the influence of zonal electric field of seismogenic origin as the most probable reason of the pre-earthquake $\mathrm{NmF} 2$ and TEC disturbances [20-22]. In the middle latitudes the upward electromagnetic drift, created by the eastward electric field, leads to the increase of the NmF2 and TEC due to the plasma transport to the regions with lower concentration of the neutral molecules and, consequently, with lower loss rate of dominating ions $\mathrm{O}^{+}$in the ionmolecular reactions. The electric field of the opposite direction (westward) creates the opposite (negative) effect in NmF2 and TEC. In the low latitude regions the increase of the eastward electric field leads to the deepening of the Appleton anomaly minimum ("trough" over the magnetic equator in the latitudinal distribution of electron concentration) due to the intensification of the fountain-effect.

Convective transportation of charged aerosols and their gravitational sedimentation in the atmosphere as well as radon and other radioactive elements emanation into the lower atmosphere over the faults leads to increase of the atmospheric radioactivity level during earthquake formation [3,5,23-25]. It also causes enlargement of the ionization and electric conductivity of the near-ground atmosphere. The joint action of these processes increases the electric field in the ionospheric heights up to units-tens $\mathrm{mV} / \mathrm{m}$ [23-26]. Numerical simulations using the Upper Atmosphere Model (it would be described below) showed that such electric fields are required to produce the observed TEC disturbances [20-22]. These estimations and calculations are also in good agreement with the INTERCOSMOS-BULGARIA-1300 satellite observations [26-29], rocket measurements of large intense electric fields in the E-layer of the ionosphere [30] and ionosonde data-derived electric fields' estimations [31] as well as with recent other authors' simulations, e.g. [32- 34].

Another mechanism of the near-ground atmosphere 
layer ionization was proposed by F. Freund [35,36]. According to his laboratory experiments electric charge carriers activate during rock stress. These carriers - the so-called "positive holes" - are highly mobile and are able to leave stressed rock volume.

The joint action of both mechanisms of near-ground atmosphere layer ionization - on the basis of "positive holes" and radon-related one-is possible.

Thus, the F2-layer ionospheric plasma' drift under action of the ionospheric electric fields of seismogenic origin is considered as the most probable reason of producing pre-earthquake TEC disturbances. This theory is supported by several features of the pre-earthquake TEC anomalies such as their geomagnetic conjugation, relation to equatorial anomaly modifications and response on sunrise terminator income and sunset terminator leaving.

\section{VERTICAL ELECTRIC CURRENTS FLOWING BETWEEN THE EARTH AND IONOSPHERE}

The principal ability to reproduce observed TEC disturbances by ionospheric electric fields of seismic origin was proved by numerical simulations for synthetic and concrete earthquakes' model case studies [12,13,21,22].

Model experiments were carried out using the Upper Atmosphere Model - global numerical model of the Earth's upper atmosphere as a whole system from the height of $80 \mathrm{~km}$ to 15 Earth's radii. The model calculates main physical parameters of the upper atmosphere such as densities, temperatures and velocities of the neutral $\left(\mathrm{O}, \mathrm{O}_{2}, \mathrm{~N}_{2}\right.$, $\mathrm{H}$ ) and charged $\left(\mathrm{O}_{2}^{+}, \mathrm{NO}^{+}, \mathrm{O}^{+}, \mathrm{H}^{+}\right.$and electrons $)$species by numerical integration of the continuity, momentum and heat balance equations as well as the equation of the electric field potential [37-40].

To build the model difference maps of the TEC we first performed a regular calculation without any additional electric current sources to use these results as quiet background values. Then, an external electric current flowing between the lower atmosphere and the ionosphere presumably of seismogenic origin was used as a model input for the calculations of the ionospheric field and the corresponding TEC variations. Additional sources of the electric current were switched on at the lower boundary $(80 \mathrm{~km})$ in the UAM electric potential equation, which was solved numerically jointly with all other UAM equations for neutral and ionized gases.

It was shown that electric fields that are able to produce observed pre-earthquake TEC deviations should be of about $1-4 \mathrm{mV} / \mathrm{m}$ in case of the low-latitudes and about $4-10 \mathrm{mV} / \mathrm{m}$ in case of the mid-latitudes [11-13, 21,22]. According to estimations obtained in [23-25], the external current with density of about $1000 \mathrm{nA} / \mathrm{m}^{2}$ at the area of about $200 \mathrm{~km}$ in radius is required to create the electric field of about several $\mathrm{mV} / \mathrm{m}$ in the ionosphere.
Such current density is quite huge and its value is $10^{6}$ times larger than the regular "fair-weather" vertical electric currents' density. Nevertheless, such anomalous currents are reported in several experiments and measurements.

For example, the current of $10-25 \mathrm{nA}$ was registered on a $200 \mathrm{~cm}^{2}$ collector plate in the laboratory experiments with stressed rocks mentioned above [35,36]. It corresponds to the densities of about $500-1250 \mathrm{nA} / \mathrm{m}^{2}$. The current with typical value of $2500 \mathrm{nA}$ flowed through the average cross section of the trunk of $0.5 \mathrm{~m}^{2}$ [41]. It corresponds to the current density of $500-1000 \mathrm{nA} / \mathrm{m}^{2}$. The average Maxwell current density under a small Florida thunderstorm ranged from 1 to $4 \mathrm{nA} / \mathrm{m}^{2}$ for a short period of time according to [42]. Finally, the current with density up to $20 \mathrm{nA} / \mathrm{m}^{2}$ flowed upward from thunderstorm areas as it was obtained in airplane measurements [43].

Different magnitudes of the vertical electric currents flowing between the Earth and ionosphere were investigated in the numerical simulations using the Upper Atmosphere Model [11-13,20-22]. It was obtained that additional electric currents of about $1000 \mathrm{nA} / \mathrm{m}^{2}$ switched on at the height of about $80 \mathrm{~km}$ over the area approximately 500 by $200 \mathrm{~km}$ produce extremely strong TEC disturbances. On the other hand, electric currents with the density of about $1-5 \mathrm{nA} / \mathrm{m}^{2}$ over the same area triggered TEC disturbances not exceeding 15\% - 30\% in magnitude relatively to non-disturbed conditions.

The results that are much closer to the observed were achieved by setting up external electric currents with density of $20 \mathrm{nA} / \mathrm{m}^{2}$ over the area of about $200 \mathrm{~km}$ along meridian and about $2000 \mathrm{~km}$ along the parallel. TEC disturbances produced by this configuration have reached $30 \%$ - $50 \%$ by magnitude depending on the current's spatial distribution and lifetime. The model TEC deviations' magnitudes, lifetime, dimensions, magnetically conjugation, response on sunlit ionosphere approach and leaving were in good agreement with observations. On the other hand, the model negative disturbances occupied the bigger area than positive ones in contrast with observations. Both calculated and observed TEC disturbances were asymmetric relative to the magnetic equator.

Ionospheric response on vertical electric currents was studied further by varying such parameters of the currents as direction (to or from the ionosphere), latitudinal position $\left(5^{\circ}-45^{\circ} \mathrm{mag}\right.$. lat.) and configuration in [44].

In order to maintain the total current in global electric circuit the "back" ("return") currents were taken into account. Simulation results showed that configurations with external ("straight") currents switched on over the epicenter with currents of opposite direction ("back" currents) spread out over the globe produce TEC disturbances very similar to those that were created by the 
same configurations but without any "back" currents.

Changing direction of the "straight" currents led to the "mirror reverse" of the positive and negative disturbances relatively to the magnetic meridian crossing the epicenter and magnetically conjugated area.

The model calculated electric potential and TEC disturbances depend on the latitude of the electric current sources, as it is seen in Figure 2: the amplitudes are maximal near $30^{\circ}$ mag. lat.

Similar numerical calculations were performed in [45]. They simulated only TEC response at the epicenter region and did not consider magnetically conjugated ones. The simulations were local (not for the globe as in our case) with "single" point source. According to their simulations using SAMI3 model the current density of $0.2-10 \mu \mathrm{A} / \mathrm{m}^{2}$ in the earthquake fault zone can cause TEC variations of up to $2 \%-25 \%$ in the daytime ionosphere and the density of $0.01-1 \mu \mathrm{A} / \mathrm{m}^{2}$ can lead to nighttime TEC variations of $1 \%-30 \%$. Such huge currents' densities are required due to a too small area of the current generation in their simulation. Beside of this, our and their model results do not contradict each other.

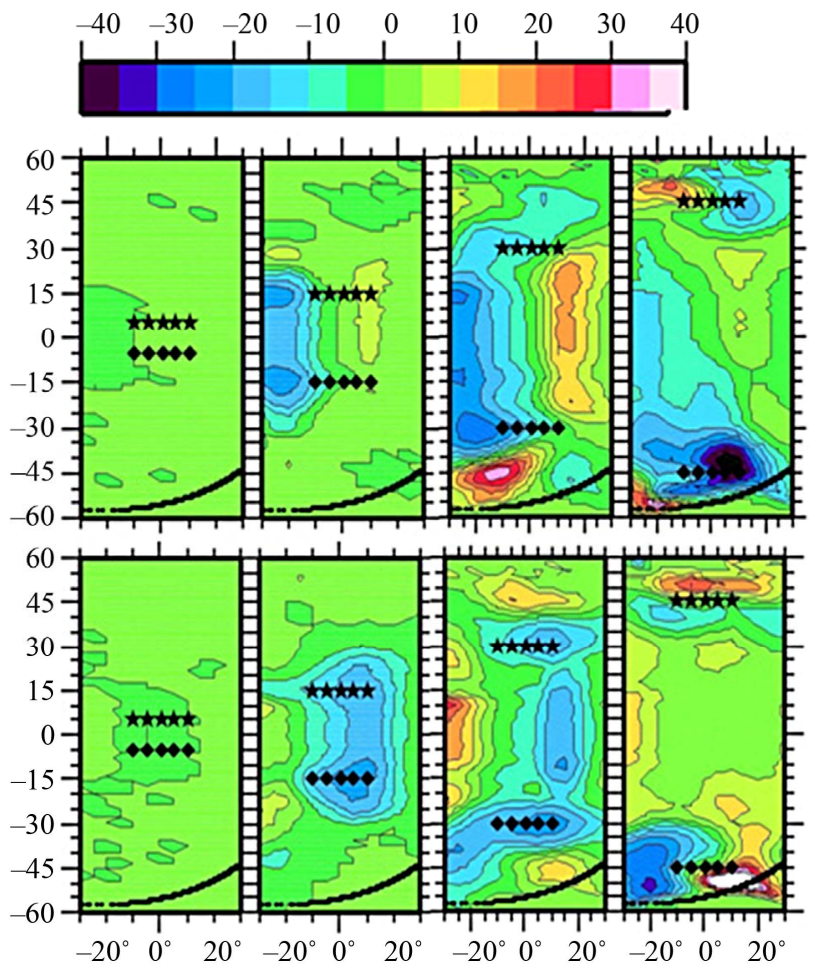

Figure 2. Calculated TEC disturbances (\%) relative to nondisturbed conditions for different current sources' position (from left to right) at 01:00 LT. Current flow to the Earth (top row) and to the ionosphere (bottom row). Star and diamond denote the epicenter position and magnetically conjugated point respectively. Black line and orange circle correspond to the terminator and sub-solar point. Coordinates are the geomagnetic latitude and longitude. Local time labels corresponds to the earthquake' epicenter position.

\section{CALCULATED THREE-DIMENSIONAL STRUCTURE OF THE ELECTRON DENSITY DISTURBANCES}

Let us now consider the calculated three-dimensional structure of the electron density presented in Figure 3. The configuration with vertical electric currents switched on at the $30^{\circ}$ mag. lat. will be discussed. Middle column corresponds to the epicenter longitude ( $30^{\circ} \mathrm{mag}$. long.). Left and right columns correspond to the longitudes that are $15^{\circ}$ west and east respectively $\left(345^{\circ}\right.$ and $15^{\circ}$ mag. long.), i.e., to those magnetic meridians where strongest TEC disturbances were obtained.

First of all, it should be noticed that $\mathrm{NmF} 2$ and $\mathrm{HmF} 2$ are higher in the Southern (summer) Hemisphere than in the Northern (winter) one for non-disturbed conditions (see top row in Figure 3). Asymmetry of the TEC disturbances caused by the vertical electric currents can be explained by these differences, i.e., by different ionospheric conditions in winter and summer Hemispheres.

As the most probable physical mechanism that produce pre-earthquake NmF2 and TEC disturbances we consider the vertical drift of the F2-layer ionospheric plasma under the influence of zonal electric field of seismogenic origin [20-22]. According to this hypothesis eastward electric field leads to the vertical plasma transport upwards to the regions where concentration of neutral molecules is low (loss rate of dominating ions $\mathrm{O}+$ in ion-molecular reactions is low). Thus, eastward electric field in middle latitudes leads to the increase of the $\mathrm{NmF} 2$ and TEC; westward electric field causes negative effect.

Actually, plasma movement is more complicated. The electric field produced by additional vertical electric currents is directed perpendicularly to the magnetic field and radially from it (if electric charge was delivered from below) or towards the magnetic field (if electric charge was delivered from above). Direction of the $[\mathbf{E} \times \mathbf{B}]$ drift, in turn, is perpendicular to both electric and magnetic fields. The plasma drift has all three components-vertical, meridional and zonal. Depending on position in the space, the sign of each component may be changed to the opposite one. The action of vertical components of both signs leads to the increase (or decrease) of the electric number density, while the action of meridional and zonal components moves plasma in horizontal plane, i.e. redistributes it.

The result of the physical process described above is shown in Figure 3 (see also [46]). According to the simulations both crests of Appleton anomaly displaced not only in vertical direction but also from the equator and along the parallels in the disturbed conditions (middle row in Figure 3) relatively to the quiet conditions (top 


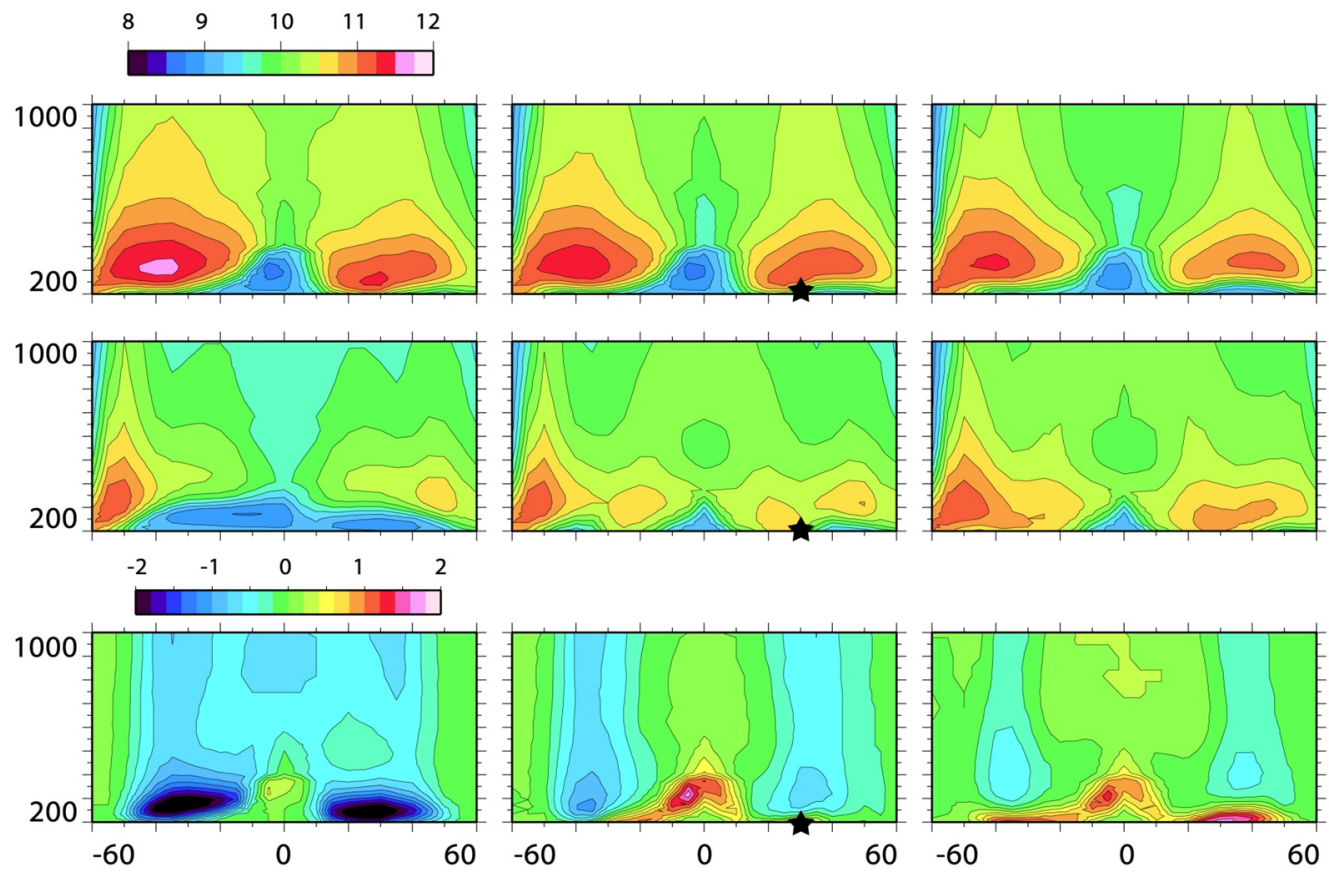

Figure 3. The calculated altitude-latitude sections of the electron density logarithms for 01:00LT along the epicenter longitude (middle column) and $15^{\circ}$ west and east from it (the left and right columns respectively). From top to bottom: the quiet, disturbed values and differences between disturbed and nondisturbed values. Star denotes the epicenter latitude $\left(30^{\circ} \mathrm{mag}\right.$. lat.).

row in Figure 3). The HmF2 changed insignificantly or decreased depending on the magnetic latitude and the longitude. As regards the $\mathrm{NmF} 2$, it changed dramatically. For example, at 01:00 LT the strongest negative disturbances were obtained along $345^{\circ}$ mag. long. $\left(15^{\circ}\right.$ to the west from epicenter longitude) and at the areas from $20^{\circ}$ to $40^{\circ}$ mag. lat. and from $-20^{\circ}$ to $-40^{\circ}$ mag. lat., i.e. at epicenter latitude and magnetically conjugated area. The positive disturbances were obtained along $15^{\circ}$ mag. longitude ( $15^{\circ}$ to the east from epicenter longitude) from about $-30^{\circ}$ to $+30^{\circ}$ mag. lat. (see Figure 2 and bottom row in Figure 3).

Thus, UAM calculations strongly support previously supposed hypothesis of plasma drift in producing preearthquake anomalies, where vertical drift plays major role in increase (decrease) of the electron number density due to correspondingly decrease (increase) of the ion $\mathrm{O}^{+}$ loss rate and the horizontal drifts redistribute plasma along the meridians and the parallels.

\section{CONCLUSIONS}

In this paper the "extended" set of pre-earthquake TEC disturbances' features is proposed. Strong earthquake statistics analysis revealed that such anomalies existed in two thirds of investigated events during 2005- 2006. The electromagnetic F2-layer ionospheric plasma drift under action of the electric field of seismic origin is proposed as the main reason of the observed phenomena. This hy- pothesis is supported by the magnetic conjugation of the observed TEC anomalies, related equatorial anomaly modifications and their response on sunlit ionosphere income as well as by the results of the numerical simulations using the Upper Atmosphere Model (UAM).

Model results show that vertical electric currents with density of about $20 \mathrm{nA} / \mathrm{m}^{2}$ flowing over area of about 200 by $2000 \mathrm{~km}$ between the Earth and ionosphere are required to produce such TEC disturbances. Current density amplitude is much larger than regular values of "fairweather" current density but such extreme values are also observed.

The ionosphere response on the vertical electric currents' parameters have been investigated using UAM. The strongest anomalies were obtained for sources acting near $30^{\circ} \mathrm{mag}$. lat. It was also shown that "back" currents spread out over the whole Earth (with the direction opposite to the "straight" ones) have no influence on producing TEC deviations by comparison with configurations without any "back" currents. Changing of the direction of "straight" currents led to the "mirror reverse" of the positive and negative deviations relatively to the magnetic meridian of the earthquake epicenter. Their asymmetry relatively to the magnetic equator was explained by different ionospheric conditions in the winter and summer Hemispheres.

Calculated three-dimensional structure of electron density have shown importance of not only vertical but also 
horizontal components of the ionospheric plasma drift in producing the TEC disturbances observed before the strong earthquakes.

\section{REFERENCES}

[1] Liu, J.Y., Chuo, Y.J., Shan, S.J., Tsai, Y.B., Chen, Y.I., Pulinets, S.A. and Yu, S.B. (2004) Pre-earthquake ionospheric anomalies registered by continuous GPS TEC measurements. Annales Geophysicae, 22, 1585-1593. doi:10.5194/angeo-22-1585-2004

[2] Liu, J.Y., Chen, Y.I., Chuo, Y.J. and Chen, C.S. (2006) A statistical investigation of preearthquake ionospheric anomaly. Journal of Geophysical Research, 111, A05304. doi:10.1029/2005JA011333

[3] Pulinets, S.A. (1998) Seismic activity as a source of the ionospheric variability. Advances in Space Research, 22, 903-906. doi:10.1016/S0273-1177(98)00121-5

[4] Pulinets, S.A., Legen'ka, A.D., Gaivoronskaya, T.V. and Depuev, V.Kh. (2003) Main phenomenological features of ionospheric precursors of strong earthquakes. Journal of Atmospheric and Solar-Terrestrial Physics, 65, 1337-1347. doi:10.1016/j.jastp.2003.07.011

[5] Pulinets, S.A. and Boyarchuk, K. (2004) Ionospheric precursors of earthquake. Springer, Berlin.

[6] Romanovskaya, Yu.V., Namgaladze, A.A., Zolotov, O.V., Starikova, N.A. and Lopatiy, V.Z. (2012) Searching for seismo-ionospheric earthquakes precursors: Total electron content disturbances before 2005-2006 seismic events. Proceedings of the MSTU, 15, 477-481. http://goo.gl/idiAF

[7] Zakharenkova, I.E., Krankowski, A. and Shagimuratov I.I. (2006) Modification of the low-latitude ionosphere before December 26, 2004 Indonesian earthquake. Natural Hazards and Earth System Sciences, 6, 817-823. doi:10.5194/nhess-6-817-2006

[8] Zakharenkova, I.E., Shagimuratov, I.I., Krankowski, A. and Lagovsky, A.F. (2007) Precursory phenomena observed in the total electron content measurements before great Hokkaido earthquake of September 25, 2003 (M = 8.3). Studia Geophysica et Geodaetica, 51, 267-278. doi:10.1007/s11200-007-0014-7

[9] Depueva, A.Kh. and Ruzhin, Yu.Ya. (1995) Seismoionospheric fountain-effect as analogue of active space experiment. Advances in Space Research, 15, 151-154. doi:10.1016/0273-1177(95)00036-E

[10] Depueva, A.Kh., Mikhailov, A.V., Devi M. and Barbara, A.K. (2007) Spatial and time variations in critical frequencies of the ionospheric $\mathrm{F}$ region above the zone of equatorial earthquake preparation. Geomagnetism and Aeronomy, 47, 129-133. doi:10.1134/S0016793207010197

[11] Namgaladze, A.A., Zolotov, O.V. and Prockhorov, B.E. (2011) The TEC signatures as strong seismic event precursors. Proceedings of the XXX URSI General Assembly and Scientific Symposium, Istanbul, 13-20 August 2011, 1-4. doi:10.1109/URSIGASS.2011.6051048

[12] Namgaladze, A.A., Forster, M., Prokhorov, B.E. and Zolotov, O.V. (2012) Electromagnetic drivers in the upper atmosphere: Observations and modeling. The Atmosphere and Ionosphere: Elementary Processes, Discharges and Plasmoids (Physics of Earth and Space Environments), Springer, Berlin (in Press).

[13] Namgaladze, A.A. and Zolotov, O.V. (2012) Ionospheric effects of seismogenic distrurbances of the global electric circuit seismogenic disturbances. Earthquakes Triggers Environmental Impact and Potential Hazards, Nova Publishers (in Press).

[14] Zolotov, O.V., Namgaladze, A.A., Zakharenkova, I.E., Martynenko, O.V. and Shagimuratov I.I. (2012) Physical interpretation and mathematical simulation of ionospheric precursors of earthquakes at midlatitudes. Geomagnetism and Aeronomy, 52, 390-397. doi:10.1134/S0016793212030152

[15] Zolotov, O.V., Namgaladze, A.A. and Prokhorov, B.E. (2012) Total electron content disturbances prior to Great Tohoku March 11, 2011 and October 23, 2011 Turkey Van earthquakes and their physical interpretation. Proceedings of the MSTU, 15, 477-481.

http://arxiv.org/abs/1205.6118

[16] Liperovsky, V.A., Pokhotelov, O.A., Meister, C.-V. and Liperovskaya, E.V. (2008) Physical models of coupling in the lithosphere-atmosphere-ionosphere system before earthquakes. Geomagnetism and Aeronomy, 48, 795-806. doi:10.1134/S0016793208060133

[17] Ondoh, T. (2009) Investigation of precursory phenomena in the ionosphere, atmosphere and groundwater before large earthquakes of $\mathrm{M}>6.5$. Advances in Space Research, 43, 214-223. doi:10.1016/i.asr.2008.04.003

[18] Uyeda, S., Nagao, T. and Kamogawa, M. (2009) Shortterm earthquake prediction: Current status of seismo-electromagnetics. Tectonophysics, 470, 205-213. doi:10.1016/j.tecto.2008.07.019

[19] Hayakawa, M. and Hobara, Y. (2010) Current status of seismo-electromagnetics for short-term earthquake prediction. Geomatics, Natural Hazards and Risk, 1, 115-155. doi:10.1080/19475705.2010.486933

[20] Namgaladze, A.A., Shagimuratov, I.I., Zakharenkova, I.E., Zolotov O.V. and Martynenko O.V. (2007) Possible mechanism of the TEC enhancements observed before earthquakes. Proceedings of the XXIV IUGG General Assembly, Perugia, 2-13 July 2007, p. 2091.

[21] Namgaladze, A.A., Klimenko, M.V., Klimenko, V.V. and Zakharenkova, I.E. (2009) Physical mechanism and mathematical modeling of earthquake ionospheric precursors registered in total electron content. Geomagnetism and Aeronomy, 49, 252-262. doi:10.1134/S0016793209020169

[22] Namgaladze, A.A., Zolotov, O.V., Zakharenkova, I.E., Shagimuratov, I.I. and Martynenko, O.V. (2009) Ionospheric total electron content variations observed before earthquakes: Possible physical mechanism and modeling. Proceedings of the MSTU, 12, 308-315. http://goo.gl/A8cLx

[23] Sorokin, V.M., Chmyrev, V.M. and Yaschenko, A.K. (2005) Theoretical model of DC electric field formation in the ionosphere stimulated by seismic activity. Journal of Atmospheric and Solar-Terrestrial Physics, 67, 1259-1268. doi:10.1016/i.jastp.2005.07.013 
[24] Sorokin, V.M., Yaschenko, A.K. and Hayakawa, M. (2006) Formation mechanism of the lower-ionosphere disturbances by the atmosphere electric current over a seismic region. Journal of Atmospheric and Solar-Terrestrial Physics, 68, 1260-1268. doi:10.1016/i.jastp.2006.03.005

[25] Sorokin, V.M., Yaschenko, A.K. and Hayakawa, M. (2007) A perturbation of DC electric field caused by light ion adhesion to aerosols during the growth in seismic-related atmospheric radioactivity. Natural Hazards and Earth System Sciences, 7, 155-163. doi:10.5194/nhess-7-155-2007

[26] Chmyrev, V.M., Isaev, N.V., Bilichenko, S.V. and Stanev, G.A. (1989) Observation by space-borne detectors of electric fields and hydromagnetic waves in the ionosphere over on earthquake center. Physics of the Earth and Planetary Interiors, 57, 110-114. doi:10.1016/0031-9201(89)90220-3

[27] Gousheva, M., Glavcheva, R., Danov, D., Angelov, P., Hristov, P., Kirov, B.B. and Georgieva, K. (2006) Satellite monitoring of anomalous effects in the ionosphere probably related to strong earthquakes. Advances in Space Research, 37, 660-665.doi:10.1016/j.asr.2004.12.050

[28] Gousheva, M.N., Glavcheva, R.P., Danov, D.L., Hristov, P.L., Kirov, B.B. and Georgieva, K.Y. (2008) Electric field and ion density anomalies in the mid latitude ionosphere: Possible connection with earthquakes. Advances in Space Research, 42, 206-212. doi:10.1016/j.asr.2008.01.015

[29] Gousheva, M., Danov, D., Hristov, P. and Matova, M. (2009) Ionospheric quasi-static electric field anomalies during seismic activity in August-September 1981. Natural Hazards and Earth System Sciences, 9, 3-15. doi:10.5194/nhess-9-3-2009

[30] Yokoyama, T., Yamamoto, M., Pfaff, R.F., Fukao, S. and Iwagami, N. (2002) SEEK-2 campaign measurement of the electric field in the E-region and its association with the QP echoes. Abstracts for the 112th SGEPSS Fall Meeting, Tokyo, 11 November 2002, 12-13.

[31] Xu, T., Hu, Ya., Wu, J., Wu, Z., Li, Ch., Xu, and Suo, Y. (2011) Anomalous enhancement of electric field derived from ionosonde data before the great Wenchuan earthquake. Advances in Space Research, 47, 1001-1005. doi:10.1016/j.asr.2010.11.006

[32] Klimenko, M.V., Klimenko, V.V., Zakharenkova, I.E., Pulinets, S.A., Zhao, B. and Tsidilina, M.N. (2011) Formation mechanism of great positive TEC disturbances prior to Wenchuan earthquake on May 12, 2008. Advances in Space Research, 48, 488-499. doi:10.1016/j.asr.2011.03.040

[33] Klimenko, M.V., Klimenko, V.V., Zakharenkova, I.E. and Pulinets, S.A. (2012) Variations of equatorial electrojet as possible seismo-ionospheric precursor at the occurrence of TEC anomalies before strong earthquake. Advances in Space Research, 49, 509-517. doi:10.1016/j.asr.2011.10.017

[34] Liu, J.Y., Le, H., Chen, Y.I., Chen, C.H., Liu, L., Wan, W., Su, Y.Z., Sun, Y.Y., Lin, C.H. and Chen, M.Q. (2011) Observations and simulations of seismoionospheric GPS total electron content anomalies before the 12 January 2010 M7 Haiti earthquake. Journal of Geophysical Research, 116, A04302. doi:10.1029/2010JA015704

[35] Freund, F.T., Kulahci, I.G., Cyr, G., Ling, J., Winnick, M., Tregloan-Reed, J. and Freund, M.M. (2009) Air ionization at rock surfaces and pre-earthquake signals. Journal of Atmospheric and Solar-Terrestrial Physics, 71, 18241834. doi:10.1016/j.jastp.2009.07.013

[36] Freund, F. (2011) Pre-earthquake signals: Underlying physical processes. Journal of Asian Earth Sciences, 41, 383400. doi:10.1016/j.jseaes.2010.03.009

[37] Namgaladze, A.A., Korenkov, Yu.N., Klimenko, V.V., Karpov, I.V., Bessarab, F.S., Surotkin, V.A., Glushchenko, T.A. and Naumova, N.M. (1988) Global model of the thermosphere-ionosphere-protonosphere system. Pure and Applied Geophysics, 127, 219-254. doi:10.1007/BF00879812

[38] Namgaladze, A.A., Korenkov, Yu.N., Klimenko, V.V., Karpov, I.V., Surotkin, V.A. and Naumova, N.M. (1991) Numerical modeling of the thermosphere-ionosphere-protonosphere system. Journal of Atmospheric and Solar-Terrestrial Physics, 53, 1113-1124. doi:10.1016/0021-9169(91)90060-K

[39] Namgaladze, A.A., Martynenko, O.V., Volkov, M.A., Namgaladze, A.N. and Yurik, R.Yu. (1998) High-latitude version of the global numeric model of the Earth's upper atmosphere. Proceedings of the MSTU, 1, 23-84. http://goo.gl/8x9f2

[40] Namgaladze, A.A., Martynenko, O.V. and Namgaladze, A.N. (1998) Global model of the upper atmosphere with variable latitudinal integration step. International Journal of Geomagnetism and Aeronomy, 1, 53-58.

[41] Le Mouel, J.-L., Gibert, D. and Poirier, J.-P. (2010) On transient electric potential variations in a standing tree and atmospheric electricity. Comptes Rendus Geoscience, 342, 95-99. doi:10.1016/j.crte.2009.12.001

[42] Krider, E.P. and Musser, J.A. (1982) Maxwell currents under thunderstorms. Journal of Geophysical Research, 87, 11171-11176. doi:10.1029/JC087iC13p11171

[43] Blakeslee, R. J., Christian, H. J. and Vonnegut, B. (1989), Electrical measurements over thunderstorms, Journal of Geophysical Research, 94, 13135. doi:10.1029/JD094iD11p13135

[44] Karpov, M.I., Zolotov, O.V. and Namgaladze, A.A. (2012) Modeling of the ionosphere response on the earthquake preparation. Proceedings of the MSTU, 15, 471-476. http://goo.gl/t2aoy

[45] Kuo, C.L., Huba, J.D., Joyce, G. and Lee, L.C. (2011) Ionosphere plasma bubbles and density variations induced by pre-earthquake rock currents and associated surface charges. Journal of Geophysical Research, 116, 10. doi:10.1029/2011JA016628

[46] Karpov, M.I., Namgaladze, A.A. and Zolotov, O.V. (2012) Three-dimensional structure of the seismo-electromagnetic ionospheric electron density disturbances. Proceedings of the MSTU, 15, 595-603. http://goo.gl/oi2gq 